\title{
Controle de PAPUÃ (Brachiaria plantaginea) EM SOJA EM FunÇÃo da Dose e da ÉPOCA dE APLICAÇÃo do HERBICIDA Clethodim ${ }^{1}$
}

\author{
Control of Alexandergrass (Brachiaria plantaginea) in Soybean as a Function of Clethodim \\ Herbicide Application Rate and Timing
}

FLECK, N.G. ${ }^{2}$, LAZAROTO, C.A. ${ }^{3}$, SCHAEDLER, C.E. ${ }^{4}$ e FERREIRA, F.B. ${ }^{3}$

\begin{abstract}
RESUMO - Herbicidas podem apresentar diferentes niveis de controle de plantas daninhas, em função de espécies presentes na área, estádio de desenvolvimento, dose do herbicida e condições de aplicação e de ambiente. Os objetivos deste trabalho foram investigar a possibilidade de uso de dose reduzida do herbicida graminicida clethodim, aplicado em pósemergência, para controlar papuã em soja e quantificar a influência da época de aplicação do controle químico sobre variáveis agronômicas da cultura. O experimento foi instalado na EEA/UFRGS, em Eldorado do Sul, RS, no ano agrícola 2005/06. O cultivar de soja utilizado foi Fepagro-RS 10, semeado em espaçamento entre fileiras de $25 \mathrm{~cm}$. Os fatores e tratamentos comparados foram: doses do herbicida clethodim (96 e $60 \mathrm{~g} \mathrm{ha}^{-1}$ ) e épocas do controle químico de papuã (de 3 até 39 dias após emergência da soja). Foram mantidas testemunhas com presença e ausência de papuã, em espaçamentos entre fileiras de soja de 25 e $50 \mathrm{~cm}$. Avaliaram-se variáveis relacionadas à produtividade de grãos e outras características agronômicas de soja. É viável reduzir a dose do herbicida clethodim em 38\% para controlar papuã em soja. Quando não há controle do papuã, a redução do espaçamento entre fileiras de soja de 50 para $25 \mathrm{~cm}$ aumenta seu potencial competitivo e a produtividade de grãos, diferença não observada quando há controle da infestante. Uma única aplicação do herbicida clethodim na dose recomendada ou em dose reduzida, realizada entre os estádios $\mathrm{V}_{1}$ e $\mathrm{V}_{6}$ da soja, mantém controle completo de papuã, mesmo com nove afilhos, sem afetar a produtividade de grãos da cultura.
\end{abstract}

Palavras-chave: plantas daninhas, interferência de papuã, dose herbicida reduzida, espaçamento entre fileiras.

ABSTRACT - Herbicides may provide different levels of weed control, as a function of species present in the area, growth stage, product rate and application and environmental conditions. The objectives of this study were to investigate the possibility of using a reduced rate of the grass herbicide clethodim, applied in postemergence, for Alexandergrass control in soybean and to quantify the influence of application time of chemical control on agronomic traits of the crop. The experiment was set up at EEA/UFRGS, in Eldorado do Sul, RS, during the 2005/2006 growing season. The soybean cultivartested was Fepagro-RS 10, seeded at row spacing of $0.25 \mathrm{~cm}$. The factors and treatments compared were: clethodim rates (96 and $60 \mathrm{~g} \mathrm{ha}^{-1}$ ) and herbicide application times (from 3 to 39 days after soybean emergence). Check plots with and without Alexandergrass infestation were included using soybean row spacing widths of 0.25 and $0.50 \mathrm{~cm}$. Variables related to soybean yield and other agronomic characteristics of the crop were evaluated. It is viable to reduce the herbicide clethodim rate in 38\% for Alexandergrass control. Without

1 Recebido para publicação em 4.6.2007 e na forma revisada em 27.3.2008

2 Engo-Agr ${ }^{0}$, Ph.D, Prof. do Dep. de Plantas de Lavoura da Faculdade de Agronomia, UFRGS, Caixa Postal 15100, 91501-970, Porto Alegre-RS, bolsista de Produtividade em Pesquisa do CNPq; ${ }^{3}$ Engo-Agr ${ }^{0}$, aluno do Programa de Pós-Graduação em Fitotecnia, UFRGS, <calazaroto@yahoo.com.br>, autor para correspondência; ${ }^{4}$ Aluno do Curso de Graduação em Agronomia, UFRGS, bolsista de iniciação científica do CNPq.

Planta Daninha, Viçosa-MG, v. 26, n. 2, p. 375-383, 2008 
Alexandergrass, control soybean row spacing reduction from 0.50 to $0.25 \mathrm{~cm}$ increases the competitive capacity of the crop and grain yield as well, a difference not observed under weed control. A single application of clethodim, either at the label rate or at a reduced rate, between soybean $V_{1}$ and $V_{6}$ growth stages, maintains complete Alexandergrass control, even when the grass plants present nine tillers, without affecting crop grain yield.

Keywords: weeds, Alexandergrass interference, reduced herbicide rate, crop row spacing.

\section{INTRODUÇÃO}

Herbicidas podem apresentar diferentes níveis de controle de plantas daninhas, em função de espécies presentes na área, estádio de desenvolvimento, dose do herbicida e condições de aplicação e de ambiente. O controle eficiente de plantas daninhas com o uso de herbicidas em pós-emergência depende, sobretudo, do estádio de desenvolvimento delas (Askew et al., 2000; Johnson \& Hoverstad, 2002). À medida que a aplicação for atrasada, há menor eficiência de controle, pelo fato de as plantas daninhas apresentarem maior desenvolvimento vegetativo e tolerância aos herbicidas. Em soja, o controle de papuã foi reduzido de 99 para 86\% devido ao atraso da aplicação de 28 para 36 dias após a emergência da cultura (Fleck et al., 1997). Por sua vez, o controle efetuado precocemente permite que ele seja realizado quando as plantas daninhas apresentam menor desenvolvimento vegetativo e maior suscetibilidade ao herbicida. Atraso no controle das plantas daninhas aumenta o período de convivência das culturas com estas plantas, o que pode aumentar as perdas em produtividade de grãos (Hall et al., 1992; Van Acker et al., 1993).

Ao longo dos anos, foram desenvolvidos diversos herbicidas eficazes para uso em culturas, muitos dos quais para utilização em soja, oportunizando, desse modo, ação reparadora no controle de plantas daninhas. Em soja, uma das estratégias empregadas refere-se à utilização de práticas de manejo conjugadas com métodos químicos de controle. Nas últimas décadas, técnicos e agricultores vêm buscando formas de reduzir os custos de produção, de modo a tornar a cultura da soja mais competitiva no mercado global. Nesse sentido, a utilização de doses elevadas de herbicidas vem sendo intensamente questionada, em razão de possíveis danos ao ambiente, bem como por seu custo elevado. Dentre os métodos propostos para reduzir os custos de produção e, também, a quantidade de agroquímicos distribuídos no ambiente, incluem-se a integração de técnicas de manejo e o emprego de doses herbicidas abaixo daquelas usualmente recomendadas pelos fabricantes. A dose reduzida de herbicida satisfaz, em parte, as necessidades ambientais e de redução do custo de produção.

As doses de herbicidas constantes nos rótulos dos produtos estão, muitas vezes, em níveis mais altos do que os necessários para que o controle das plantas daninhas seja efetivamente garantido em amplas condições de ambiente e manejo (Zhang et al., 2000; Doyle \& Stypa, 2004). As doses recomendadas pelos fabricantes pretendem assegurar elevado controle sobre ampla gama de espécies daninhas, de variada suscetibilidade, mesmo em condições que podem não ser as ideais para a atividade do produto.

Niveis satisfatórios de controle de plantas daninhas freqüentemente são obtidos com uso de doses de herbicidas abaixo daquelas recomendadas nos rótulos dos produtos. Várias pesquisas demonstram ser possivel reduzir as doses sem causar prejuízo no controle de plantas daninhas e sem afetar a produtividade das culturas (Zhang et al., 2000; O'Donovan et al., 2001; Boström \& Fogelfors, 2002; Hamill et al., 2004).

Pesquisa comprovou ser viável a adoção da tecnologia de redução de doses de herbicidas graminicidas para metade daquelas usuais, alcançando controle de papuã e produtividade de grãos de soja equivalentes àqueles obtidos com as doses normalmente recomendadas (Fleck et al., 1997). Ainda, o trabalho 
indicou ser viável utilizar apenas meia dose de herbicidas graminicidas para controle de papuã em soja, desde que a aplicação seja realizada até a quarta semana após emergência da cultura. Estudos relacionados sugerem, também, que é possível aumentar o retorno econômico com o uso de doses reduzidas de herbicidas, desde que aplicadas em conjunto com medidas de manejo integrado de plantas daninhas (Boström et al., 2000; Popp et al., 2000). Resultados similares foram relatados por Walker et al. (2002), porém, neste caso, a redução da dose herbicida dependeu da densidade e do estádio das plantas daninhas.

A dose de herbicida que apenas reduz ou suprime o crescimento das plantas daninhas, neutralizando sua interferência na cultura, é denominada "dose economicamente ótima", a qual, normalmente, é bem inferior à dose referida no rótulo do produto (Dieleman et al., 1996). Em conseqüência, a redução nas doses dos herbicidas, mantendo-se adequado controle de plantas daninhas, resulta em aumento no lucro do produtor e na diminuição do impacto negativo do produto no ambiente. Nesse sentido, a aplicação de herbicida sobre plantas daninhas jovens é fator crítico em permitir redução de dose, já que nos estádios iniciais de crescimento elas são consideravelmente mais suscetiveis do que plantas em estádios mais avançados, as quais exigirão doses maiores para serem eliminadas. Por exemplo, Rizzardi \& Fleck (2004) testaram a mistura dos herbicidas acifluorfen + bentazon para controle das espécies daninhas guanxuma (Sida rhombifolia) e picão-preto (Bidens spp.) em soja, utilizando doses do produto comercial variáveis entre 1,25 e a dose de rótulo de $2,0 \mathrm{~L} \mathrm{ha}^{-1}$. Constataram que a dose de rótulo foi a que se mostrou biologicamente mais eficaz; contudo, dose próxima a $75 \%$ da dose de rótulo foi a que mais compensou, economicamente, a adoção do controle químico.

O sucesso do uso de herbicidas em pósemergência depende da habilidade do produtor em determinar o momento correto de controlar as plantas daninhas. Nesse aspecto, muitas vezes, com a integração de práticas de manejo, as doses de herbicidas podem ser reduzidas e, ainda assim, prover controle satisfatório dessas plantas (Mohler, 2001; Nazarko et al., 2005). Uma prática importante a considerar na adoção do manejo cultural de plantas daninhas refere-se à redução do espaçamento entre fileiras da cultura. A aproximação das fileiras, mantida a densidade de plantas, distribui melhor as plantas, reduzindo a interferência intra-específica. Em decorrência, pode incrementar a matéria seca e a área foliar e, principalmente, possibilitar maior e mais rápida interceptação da radiação solar, em virtude da melhor distribuição das plantas na área, resultando em maior produtividade de grãos (Ventimiglia et al., 1999; Pires et al., 2000).

Os objetivos deste trabalho foram investigar a possibilidade de uso de dose reduzida do herbicida graminicida clethodim, aplicado em pós-emergência, para controlar papuã em soja e quantificar a influência da época de aplicação do controle químico sobre variáveis agronômicas da cultura.

\section{MATERIAL E MÉTODOS}

Foi conduzido um experimento em campo no ano agrícola 2005/06, na Estação Experimental Agronômica da Universidade Federal do Rio Grande do Sul (EEA/UFRGS), localizada em Eldorado do Sul, região fisiográfica da Depressão Central do Estado do Rio Grande do Sul. O solo da área experimental está classificado como Latossolo Vermelho distrófico típico, pertencendo à unidade de mapeamento São Jerônimo (Embrapa, 1999). O solo da área apresentava as seguintes propriedades: argila, $26 \%$; $\mathrm{MO}, 2,7 \%$; $\mathrm{pH}$ (em água), 6, 1 ; indice SMP, 6,6; $\mathrm{P}$, 9,0 mg L-1; K, $204 \mathrm{mg} \mathrm{L}^{-1}$; Al, 0 cmol $_{\mathrm{c}} \mathrm{L}^{-1}$; Ca, $4,3 \mathrm{cmol}_{\mathrm{c}} \mathrm{L}^{-1} ; \mathrm{Mg}, 2 \mathrm{cmol}_{\mathrm{c}} \mathrm{L}^{-1}$; e CTC efetiva, $9,0 \mathrm{cmol}_{\mathrm{c}}^{\mathrm{C}} \mathrm{L}^{-1}$.

O experimento foi implantado em sistema de semeadura direta, em sucessão ao trigo. $\mathrm{O}$ manejo da cobertura vegetal presente na área foi realizado em novembro e consistiu na pulverização dos herbicidas glyphosate $\left(1.080 \mathrm{~g} \mathrm{ha}^{-1}\right)$, paraquat + diquat $(300+$ $100 \mathrm{~g} \mathrm{ha}^{-1}$ ) e glyphosate (900 $\left.\mathrm{g} \mathrm{ha}^{-1}\right)$, aplicados aos 31, 26 e 3 dias antes da semeadura da soja, respectivamente. O controle das espécies daninhas dicotiledôneas que se estabeleceram no experimento foi efetuado por meio da aplicação dos herbicidas bentazon + lactofen (600 $+120 \mathrm{~g} \mathrm{ha}^{-1}$.

A área experimental esteve infestada por papuã, gramínea que ocorreu nas parcelas

Planta Daninha, Viçosa-MG, v. 26, n. 2, p. 375-383, 2008 
testemunhas em populações variáveis entre 130 e 220 plantas $\mathrm{m}^{-2}$, cuja avaliação foi realizada dez dias após a emergência (DAE) da cultura. O controle químico desta espécie foi realizado conforme as épocas indicadas na Tabela 1 , mediante aplicação do herbicida graminicida clethodim (Select $240 \mathrm{CE}$ ) nas doses de $96 \mathrm{e}$ $60 \mathrm{~g} \mathrm{ha}^{-1}$, para dose plena e dose reduzida, respectivamente, mais o adjuvante Joint Oil, usado em concentração de $0,5 \% \mathrm{v} / \mathrm{v}$. Para realizar as aplicações do herbicida, utilizou-se pulverizador costal de precisão, operando-se com bicos de jato plano, em leque, série 110.03, à pressão constante de $150 \mathrm{kPa}$, distribuindo-se volume de calda equivalente a $200 \mathrm{~L} \mathrm{ha}^{-1}$.

Tabela 1 - Épocas de realização do controle químico de papuã (Brachiaria plantaginea) e estádios de desenvolvimento da soja e da infestante por ocasião das aplicações do herbicida clethodim. EEA/UFRGS, Eldorado do Sul-RS, 2005/06

\begin{tabular}{|c|c|c|}
\hline $\begin{array}{c}\text { Épocas de aplicação } \\
(\mathrm{DAE})^{1-}\end{array}$ & Estádio da soja & Estádio do papuã \\
\hline 3 & 2 folhas simples & Até 4 folhas \\
\hline 7 & 1 folha trifoliolada & Até 3 afilhos \\
\hline 11 & 2 folhas trifolioladas & $3-5$ afilhos \\
\hline 16 & 3-4 folhas trifolioladas & $5-6$ afilhos \\
\hline 22 & 4-6 folhas trifolioladas & Até 9 afilhos \\
\hline 29 & $6-7$ folhas trifolioladas & Até 13 afilhos \\
\hline 39 & 7-8 folhas trifolioladas & Até 14 afilhos \\
\hline
\end{tabular}

${ }^{1 /} \mathrm{DAE}=$ dias após emergência da soja

O delineamento experimental utilizado foi o de blocos casualizados, com quatro repetições. Os fatores e tratamentos comparados foram: duas doses do herbicida graminicida clethodim [dose plena (96 $\mathrm{g} \mathrm{ha}^{-1}$ ) e dose reduzida (60 $\left.\mathrm{g} \mathrm{ha}^{-1}\right)$ ]; e sete épocas de controle de papuã (Tabela 1). Cada unidade experimental apresentava $12 \mathrm{~m}^{2}(3 \times 4 \mathrm{~m})$ e era formada por sete fileiras de soja espaçadas de $0,25 \mathrm{~cm}$, com área útil de $3,75 \mathrm{~m}^{2}(1,25 \times 3 \mathrm{~m})$, englobando as cinco fileiras centrais (desprezando-se $0,5 \mathrm{~cm}$ em suas extremidades). Além destes tratamentos, incluíram-se, ainda, dois tratamentos testemunhas: um sem controle e outro com controle continuado da espécie daninha alvo durante todo o ciclo da cultura. Acrescentaram-se, também, dois tratamentos testemunhas com espaçamento entre fileiras de soja de $50 \mathrm{~cm}$ : um sem controle e o outro com controle de papuã durante todo o ciclo da cultura. Nestes, estabeleceram-se quatro fileiras de soja espaçadas de $50 \mathrm{~cm}$, sendo a área útil estipulada em $3 \mathrm{~m}^{2}$ ( $1 \times 3 \mathrm{~m})$, englobando as duas fileiras centrais (desprezando-se $50 \mathrm{~cm}$ em suas extremidades).

Vinte e cinco dias antes da semeadura da soja aplicou-se a adubação ao solo, por ocasião da rolagem mecânica da cobertura vegetal. Realizou-se distribuição de adubo a lanço, em superficie, aplicando-se 25, 100 e $100 \mathrm{~kg} \mathrm{ha}^{-1}$ de $\mathrm{N}, \mathrm{P}_{2} \mathrm{O}_{5}$ e $\mathrm{K}_{2} \mathrm{O}$, respectivamente. As quantidades de nutrientes necessárias foram determinadas com base no resultado da análise de solo.

Antecedendo a semeadura, as sementes de soja foram inoculadas com Bradyrhizobium japonicum e tratadas com o fungicida captan + molibdênio $\left(118+7 \mathrm{~g} 100 \mathrm{~kg}^{-1}\right.$ de sementes). A semeadura da soja foi feita no dia 5/12/ 2005, utilizando-se o cultivar de ciclo tardio Fepagro-RS 10. A densidade de semeadura foi ajustada de acordo com o poder germinativo das sementes, objetivando-se alcançar densidades equivalentes para os dois espaçamentos entre fileiras, ou seja, dez plantas por metro para o de $25 \mathrm{~cm}$ e 20 para o de $50 \mathrm{~cm}$. Durante o desenvolvimento da cultura foram realizadas nove irrigações por aspersão e aplicações periódicas de inseticidas, para controle de pragas (Reunião..., 2005).

Logo após a colheita da soja (28/4/2006), avaliou-se visualmente a cobertura do solo pelo dossel de papuã. Para isso, utilizou-se escala percentual, em que a nota zero correspondeu a nenhuma planta de papuã na área útil da parcela e a nota 100 significou cobertura completa da parcela por plantas de papuã. A avaliação foi realizada por três avaliadores, que atribuíram individualmente suas notas, as quais foram então somadas e obtidas as respectivas médias.

As variáveis avaliadas na cultura por ocasião da colheita foram: produtividade biológica aparente da soja (PBA), estatura de planta, componentes da produtividade de grãos (número de legumes por planta, número de grãos por legume e massa do grão) e produtividade de grãos. Para obtenção dessas variáveis, exceto para produtividade de grãos, foi coletada amostra de dez plantas, aleatoriamente, em cada parcela, as quais foram cortadas ao nivel do solo. Após o corte, separaram-se os grãos do restante da planta, sendo ambas as partes 
secas em estufa com circulação forçada de ar à temperatura de $65^{\circ} \mathrm{C}$, até se obter massa constante, quando então foram pesadas.

A PBA compreendeu o somatório das massas das frações da parte aérea seca das plantas, incluindo legumes e grãos. Na mesma amostra de plantas foi determinada a estatura de planta e, também, avaliados os componentes de produtividade. A massa do grão foi obtida a partir da massa de quatro amostras de 100 grãos por parcela. Na contagem de número de legumes produtivos, considerou-se como tal todo aquele que apresentasse ao menos um grão formado (Costa \& Marchezan, 1982). Os valores numéricos do componente número de legumes foram expressos por planta. A produtividade de grãos da soja foi obtida a partir da colheita das plantas presentes na área útil das parcelas. Após trilha, limpeza e pesagem dos grãos, foi determinada sua umidade e, posteriormente, as massas foram padronizadas para $13 \%$ de umidade.

Os dados obtidos no experimento foram submetidos à análise de variância e ao teste F. Para efeito de fatores principais, adotou-se o nivel de $5 \%$ de probabilidade de erro, enquanto para a interação entre os fatores investigados adotou-se o nivel de 10\%. Quando houve interação significativa de épocas de controle de papuã e doses do herbicida, procedeu-se à análise de regressão. Os dados foram convertidos para redução percentual em relação à testemunha livre de papuã durante todo o ciclo da cultura. O critério de aceitação do modelo aos dados baseou-se na significância dos coeficientes de determinação $\left(\mathrm{R}^{2}\right)$, de modo que o maior valor representava ajuste mais satisfatório. Para avaliar a associação entre variáveis, foi realizada análise de correlação linear simples.

Para comparar os efeitos de doses do herbicida e épocas de aplicação em relação às testemunhas, os dados foram submetidos à análise de variância e ao teste de Dunnett, ambos em nivel de $5 \%$ de probabilidade. Nesse caso, as médias dos tratamentos herbicidas, testados em diferentes épocas, foram comparadas às dos tratamentos testemunhas, com espaçamento entre fileiras de $25 \mathrm{~cm}$, com e sem controle durante todo o ciclo da cultura.

Para comparar os efeitos dos tratamentos testemunhas com e sem controle, em espaçamentos entre fileiras de 25 e $50 \mathrm{~cm}$, os dados foram submetidos à análise de variância e ao teste $\mathrm{F}$, adotando-se o nível de $5 \%$ de probabilidade de erro. As médias dos tratamentos foram, então, comparadas aplicando-se o teste de Duncan a $5 \%$ de probabilidade. As análises estatísticas foram realizadas com auxílio do programa computacional SAS (SAS, 1999).

\section{RESULTADOS E DISCUSSÃO}

Não houve interação entre os fatores dose de herbicida e época de aplicação para as variáveis avaliadas. Contudo, houve efeito do fator época de aplicação do herbicida clethodim para as variáveis cobertura do solo por papuã, estatura de planta de soja, legumes produtivos, produtividade biológica e produtividade de grãos. A dose de clethodim afetou apenas a estatura de planta e o número de legumes produtivos por planta (dados não mostrados).

Com relação à cobertura do solo pelo dossel de papuã, avaliada na pré-colheita da soja, houve equivalência entre as duas doses testadas. Os niveis de cobertura do solo situaram-se entre 0 e 3\% - este último para aplicação mais tardia do herbicida (Tabela 2). Houve diferença significativa da última época de aplicação em relação à testemunha sem papuã. A infestação observada na última época pode decorrer de alguma ação negativa causada por estresse do ambiente no desempenho do herbicida, efeito das plantas de soja em impedir interceptação do produto ou da tolerância de plantas de papuã pelo estádio já avançado destas. Nesse sentido, Fleck et al. (1997) verificaram que tratamentos com clethodim, aplicados na dose plena ou em meia dose, foram equivalentes entre si quando efetuados aos 14, 21 e 28 DAE, alcançando eficiência entre 95 e $98 \%$ na précolheita da soja. Contudo, na aplicação realizada aos $35 \mathrm{DAE}$, o grau de controle foi inferior, em razão do estádio avançado de desenvolvimento das plantas de papuã, que, na ocasião, se encontravam com quatro afilhos ou mais.

Os niveis baixos ou ausência de cobertura do solo pelo dossel de papuã indicam que o herbicida clethodim foi eficiente no controle da espécie nos diferentes estádios de desenvolvimento em que foi aplicado e nas doses testadas. Esse fato reforça a convicção de que as diferenças nas demais variáveis avaliadas

Planta Daninha, Viçosa-MG, v. 26, n. 2, p. 375-383, 2008 
Tabela 2 - Cobertura do solo pelo dossel de papuã (Brachiaria plantaginea) avaliada na pré-colheita da soja, estatura de planta, número de legumes produtivos, produtividade biológica aparente e produtividade de grãos de soja, em função de épocas de controle de papuã, na média de duas doses do herbicida clethodim. EEA/UFRGS, Eldorado do Sul-RS, 2005/06

\begin{tabular}{|c|c|c|c|c|c|}
\hline $\begin{array}{c}\text { Época de aplicação de } \\
\text { clethodim (DAE) }\end{array}$ & $\begin{array}{c}\text { Cobertura do } \\
\text { solo } \\
(\%)\end{array}$ & $\begin{array}{c}\text { Estatura de } \\
\text { planta } \\
(\mathrm{cm})\end{array}$ & $\begin{array}{c}\text { Legumes } \\
\text { produtivos } \\
\left(\mathrm{planta}^{-1}\right)\end{array}$ & $\begin{array}{c}\text { Produtividade } \\
\text { biológica } \\
\left(\mathrm{kg} \mathrm{ha}^{-1}\right)\end{array}$ & $\begin{array}{c}\text { Produtividade } \\
\text { de grãos } \\
\left(\mathrm{kg} \mathrm{ha}^{-1}\right)\end{array}$ \\
\hline 3 & $*^{2} 0 \mathrm{~ns}^{3}$ & $* 99 \mathrm{~ns}$ & $* 54 \mathrm{~ns}$ & $* 15367 \mathrm{~ns}$ & $* 5040 \mathrm{~ns}$ \\
\hline 7 & $* 0 \mathrm{~ns}$ & $* 100 \mathrm{~ns}$ & $* 53 \mathrm{~ns}$ & $* 15218 \mathrm{~ns}$ & $* 5111 \mathrm{~ns}$ \\
\hline 11 & $* 0 \mathrm{~ns}$ & $* 100 \mathrm{~ns}$ & $* 55 \mathrm{~ns}$ & $* 15886 \mathrm{~ns}$ & $* 5109 \mathrm{~ns}$ \\
\hline 16 & $* 0 \mathrm{~ns}$ & $* 99 \mathrm{~ns}$ & $* 52 \mathrm{~ns}$ & $* 15524 \mathrm{~ns}$ & $* 5262 \mathrm{~ns}$ \\
\hline 22 & $* 0 \mathrm{~ns}$ & $* 97 \mathrm{~ns}$ & $* 53 \mathrm{~ns}$ & $* 15031 \mathrm{~ns}$ & $* 5251 \mathrm{~ns}$ \\
\hline 29 & $* 0 \mathrm{~ns}$ & $\mathrm{~ns} 95 *$ & $* 46 *$ & $\mathrm{~ns} 14204 *$ & $* 4871 \mathrm{~ns}$ \\
\hline 39 & $* 3 *$ & $\mathrm{~ns} 92 *$ & $* 45 *$ & $\mathrm{~ns} 13336 *$ & $* 4453 *$ \\
\hline Testemunha sem papuã & 0 & 100 & 56 & 16184 & 5264 \\
\hline Testemunha com papuã & 100 & 93 & 33 & 11516 & 2885 \\
\hline Coeficiente de variação $(\%)$ & $(1,0 \mathrm{e} 1,0)^{4}$ & $(2,5$ e 2,8$)$ & $(9,5$ e 10,6$)$ & $(7,8$ e 5,9$)$ & $(7,8$ e 6,0$)$ \\
\hline
\end{tabular}

1/ Dias após a emergência da soja.

* e ${ }^{\text {ns }}$ Diferenças significativas e não-significativas, respectivamente.

2/ e ${ }^{3 /}$ Comparações nas colunas com a testemunha com papuã e com a testemunha sem papuã, respectivamente, pelo teste de Dunnett a $5 \%$ de probabilidade.

4/ Coeficientes de variação referentes ao teste de Dunnett.

podem ser atribuídas, basicamente, às variações em interferência decorrentes dos períodos de convivência da soja com o papuã e não ao comprometimento de eficiência do herbicida pelo atraso na aplicação.

O atraso no controle de papuã - 29 e 39 DAE - causou redução da estatura de planta de soja (Tabela 2). Aparentemente, o efeito negativo da competição de papuã começou a se delinear a partir dos 29 DAE. Quando o controle de papuã ocorreu a partir dos $29 \mathrm{DAE}$, também houve diferença em estatura com a testemunha sem infestação (Tabela 2). Por sua vez, aplicações realizadas antes de 29 DAE diferiram daquelas da testemunha com papuã. Comparando as testemunhas, verifica-se que houve redução de $7 \%$ na estatura final de plantas de soja, decorrente da competição exercida pela graminea. A estatura é uma característica morfológica importante que interfere na competição por luz.

Os períodos de competição do papuã também afetaram o número de legumes produtivos por planta, em relação à testemunha sem papuã. Os controles realizados a partir de $29 \mathrm{DAE}$ sofreram reduções superiores a $20 \%$ no número de legumes produtivos (Figura 1). Quando o controle de papuã ocorreu a partir dos $29 \mathrm{DAE}$ também houve diferenças em relação à testemunha isenta da infestante (Tabela 2). Mesmo assim, todas as épocas de controle produziram mais legumes do que a testemunha com papuã. Comparativamente à testemunha livre de papuã, a presença da infestante causou redução de $41 \%$ no número de legumes produtivos por planta. Não houve efeito da interferência de papuã sobre o número de grãos por legume e na massa do grão (dados não mostrados).

A produtividade biológica aparente (PBA) foi afetada diferentemente pelas épocas de controle de papuã. Não houve diferença entre dose plena e dose reduzida do herbicida, as quais foram equivalentes entre si. Houve redução na PBA quando o controle ocorreu aos 29 e 39 DAE, em relação à testemunha sem infestação (Tabela 2). Controles realizados até 22 DAE produziram, em média, 34\% mais do que a testemunha infestada por papuã. A redução da PBA com o atraso na época de controle de papuã era esperada, pois nesse caso há maior período de convivência da cultura da soja com o papuã.

Quanto à produtividade de grãos de soja, não houve diferença estatística entre dose plena e dose reduzida do herbicida, as quais foram equivalentes em todas as épocas de aplicação. 

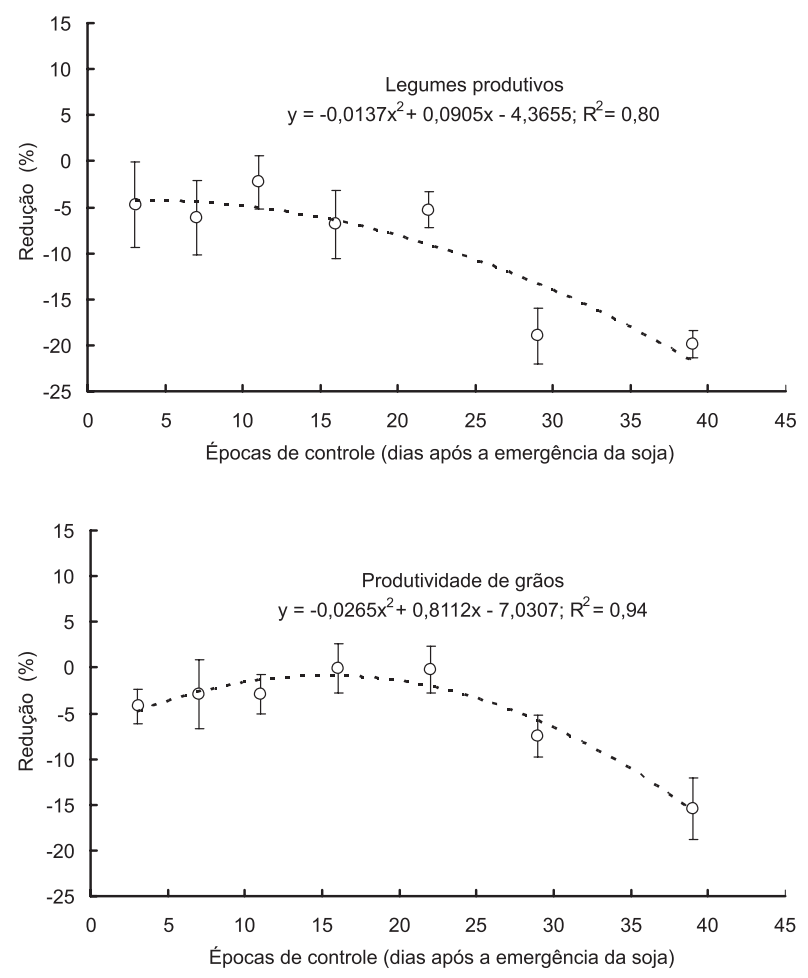

Figura 1 - Redução de legumes produtivos por planta e produtividade de grãos de soja em relação à testemunha sem papuã (Brachiaria plantaginea), em função de épocas de controle de papuã, na média de duas doses do herbicida clethodim. EEA/UFRGS, Eldorado do Sul-RS, 2005/06. Os pontos representam os valores médios e as barras, os respectivos desvios-padrão da média.

A esse respeito, Fleck et al. (1997) constataram que dose plena ou meia dose de clethodim, aplicadas aos 14, 21 ou $28 \mathrm{DAE}$, controlaram satisfatoriamente papuã e não encontraram diferenças na produtividade de grãos. Em experimento que visou controlar papuã com o herbicida haloxyfop-methyl, Fleck (1994) obteve produtividade de grãos equivalente para doses plena e reduzida. Algumas vezes, com o adequado manejo e/ou sob certas condições ambientais, as doses dos herbicidas podem ser consideravelmente reduzidas e, ainda assim, controlar com eficiência as plantas daninhas (Klingaman et al., 1992). Por outro lado, a utilização de doses reduzidas pode acabar selecionando populações de plantas resistentes aos herbicidas (Czapar et al., 1997). No presente estudo, constatou-se que todos os tratamentos com controle de papuã superaram a testemunha infestada, propiciando incrementos de produtividade de grãos variáveis entre 54 e $82 \%$ (Tabela 2).

As perdas de produtividade de grãos decorrentes da interferência exercida pelo papuã foram influenciadas pelas épocas de controle desta espécie, mas não foram afetadas pela dose do herbicida clethodim (Figura 1). As maiores produtividades relativas de grãos foram obtidas quando o controle de papuã foi realizado entre 16 e 22 DAE. A eliminação do papuã durante o ciclo da soja propiciou produtividade de grãos $45 \%$ maior do que a da testemunha infestada.

Comparando-se as épocas de controle com a testemunha livre de papuã, houve diferença apenas na última época (39 DAE), na qual a produtividade foi $15 \%$ inferior à daquela (Tabela 2). Nesse sentido, medidas de controle, se aplicadas até a quarta semana após emergência da soja (plantas no estádio de seis a sete folhas trifolioladas), preservam o potencial de produtividade de grãos da interferência ocasionada pelo papuã. Esses resultados geralmente coincidem com aqueles referidos por outros autores (Fleck et al., 2002).

Observou-se efeito do espaçamento entre fileiras de soja sobre o componente número de legumes produtivos na testemunha com papuã (Tabela 3). O mesmo não ocorreu na testemunha sem papuã. Por sua vez, na testemunha infestada, o número de legumes produtivos, no espaçamento de $25 \mathrm{~cm}$, ultrapassou em $32 \%$ aquele obtido no espaçamento de $50 \mathrm{~cm}$, o que explica, em grande parte, os resultados para produtividade de grãos. A presença permanente de papuã reduziu o número de legumes produtivos por planta em 41 e $54 \%$ para os espaçamentos de 25 e $50 \mathrm{~cm}$, respectivamente, em relação à testemunha sem papuã.

Quanto à variável massa do grão, não houve diferenças entre espaçamentos nas duas situações de interferência (Tabela 3). Contudo, nos espaçamentos de 25 e $50 \mathrm{~cm}$, houve redução de 8 e $6 \%$ na massa do grão, respectivamente, comparando-se as testemunhas com presença e ausência de papuã. Alguns trabalhos mostram que a massa do grão pode variar em função do arranjo de plantas. Nesse sentido, Moore (1991) observou que a massa e o tamanho dos grãos aumentaram quando o espaçamento entre plantas de soja era eqüidistante, e que esse aumento ocorreu também 
Tabela 3 - Número de legumes produtivos por planta, massa do grão e produtividade de grãos nas testemunhas com e sem controle de papuã, em função de espaçamentos entre fileiras de soja. EEA/UFRGS, Eldorado do Sul, RS, 2005/06

\begin{tabular}{|c|c|c|c|c|c|c|}
\hline \multirow{2}{*}{$\begin{array}{c}\text { Espaçamento } \\
(\mathrm{cm})\end{array}$} & \multicolumn{2}{|c|}{ Legume produtivo $\left(\right.$ planta $\left.^{-1}\right)$} & \multicolumn{2}{c|}{ Massa de mil grãos (g) } & \multicolumn{2}{c|}{ Produtividade de grãos $\left(\mathrm{kg} \mathrm{ha}^{-1}\right)$} \\
\cline { 2 - 7 } & $\begin{array}{c}\text { Testemunha } \\
\text { sem papuã }\end{array}$ & $\begin{array}{c}\text { Testemunha } \\
\text { com papuã }\end{array}$ & $\begin{array}{c}\text { Testemunha } \\
\text { sem papuã }\end{array}$ & $\begin{array}{c}\text { Testemunha } \\
\text { com papuã }\end{array}$ & $\begin{array}{c}\text { Testemunha } \\
\text { sem papuã }\end{array}$ & $\begin{array}{c}\text { Testemunha } \\
\text { com papuã }\end{array}$ \\
\hline 25 & A 56 a & B 33 a & A 214 a & B 196 a & A 5264 a & B 2885 a \\
\hline 50 & A 55 a & B 25 b & A 214 a & B 202 a & A 5280 a & B 1713 b \\
\hline $\begin{array}{l}\text { Coeficiente de variação (\%) } \\
\text { Controle de papuã }\end{array}$ & $24,6 \%$ & $2,3 \%$ & & \multicolumn{2}{|c|}{47,4} \\
\hline $\begin{array}{l}\text { Coeficiente de variação (\%) } \\
\text { Espaçamento entre fileira }\end{array}$ & $27,5 \%$ & $4,4 \%$ & & \multicolumn{2}{|c|}{44,7} \\
\hline
\end{tabular}

${ }^{1}$ Médias seguidas pela mesma letra, maiúscula nas linhas e minúscula nas colunas, em cada variável, não diferem significativamente pelo teste de Duncan a $5 \%$ de probabilidade.

com a diminuição da população. No entanto, em outros trabalhos não se verificou que o espaçamento entre fileiras afeta a massa do grão (Pires et al., 1998; Maehler, 2000).

As produtividades de grãos obtidas em espaçamentos entre fileiras de 25 e $50 \mathrm{~cm}$ nas testemunhas sem papuã não diferiram estatisticamente (Tabela 3). Resultados similares foram encontrados por Maehler (2000), que constatou produtividades de grãos equivalentes entre espaçamentos de 40 e $20 \mathrm{~cm}$, utilizando população de 40 plantas de soja $\mathrm{m}^{-2}$. Conforme salientado pelo autor, a redução do espaçamento entre fileiras pode não trazer benefícios em produtividade, mas também não a reduz, o que é um fato importante, já que essa prática pouco aumenta os custos de produção da lavoura. Para os espaçamentos entre fileiras de 25 e $50 \mathrm{~cm}$, testados na presente pesquisa, constataram-se reduções de 45 e $68 \%$, respectivamente, na produtividade de grãos, comparando as testemunhas com ausência e com presença de papuã (Tabela 3). Houve diferença entre os espaçamentos apenas na testemunha infestada, na qual a produtividade da soja foi $68 \%$ superior no espaçamento de $25 \mathrm{~cm}$, comparativamente ao de $50 \mathrm{~cm}$. Entretanto, outros autores relataram aumento na produtividade de grãos, com redução no espaçamento entre fileiras variável de 100 até $17 \mathrm{~cm}$, obtendo acréscimo de até 40\% (Pires et al., 1998; Ventimiglia et al., 1999).

Em decorrência desses resultados, podese concluir que, tecnicamente, é viável reduzir a dose do herbicida graminicida clethodim em até $38 \%$ para controlar a espécie daninha papuã sem ocorrer perda de eficiência ou comprometimento da produtividade de grãos de soja. Além disso, uma única aplicação do herbicida clethodim, na dose indicada ou em dose reduzida, realizada entre os estádios da soja de duas folhas simples até seis folhas trifolioladas e plantas de papuã desde uma folha até nove afilhos, mantém controle completo desta infestante e preserva inalteradas as características agronômicas da cultura. Decréscimos observados em algumas características avaliadas em soja refletem especialmente os efeitos decorrentes do atraso no controle de papuã e não da redução na eficiência do herbicida clethodim. O atraso na aplicação do herbicida clethodim quando as plantas de papuã já desenvolveram 14 afilhos e as plantas de soja alcançaram o estádio $\mathrm{V}_{7}$ a $\mathrm{V}_{8}$ reduz a produtividade de grãos da cultura. Quando não há controle da infestação de papuã, a redução do espaçamento entre fileiras de soja de 50 para $25 \mathrm{~cm}$ aumenta a capacidade competitiva da cultura e o potencial de produtividade de grãos - vantagem que inexiste entre os espaçamentos quando há controle químico da infestante.

\section{LITERATURA CITADA}

ASKEW, S. D.; SHAW, D. R.; STREET, J. E. Graminicide application timing influences red rice (Oryza sativa) control and seedhead reduction in soybean (Glycine max). Weed Technol., v. 14, n. 1, p. 176-181, 2000.

BOSTRÖM, U.; FOGELFORS, H. Long-term effects of herbicide-application strategies on weeds and yield in spring-sown cereals. Weed Sci., v. 50, n. 2, p. 196-203, 2002. 
BOSTRÖM, U.; HANSON, M.; FOGELFORS, H. Weeds and yields of spring cereals as influenced by stubblecultivation and reduced doses of herbicides in five long-term trials. J. Agric.l Sci., v. 134, n. 3, p. 237-244, 2000

COSTA, J. A.; MARCHEZAN, E. Características dos estádios de desenvolvimento da soja. Campinas: Fundação Cargill, 1982. 30 p.

CZAPAR, G. F.; CURRY, M. P.; WAX, L. M. Grower acceptance of economic thresholds for weed management in Illinois. Weed Technol., v. 11, n. 4, p. 828-831, 1997.

DIELEMAN, J. A. et al. Decision rules for post emergence control of pigweed (Amaranthus spp.) in soybean (Glycine max). Weed Sci., v. 44, n. 1, p. 126-132, 1996

DOYLE, P.; STYPA, M. Reduced herbicide rates: A canadian perspective. Weed Technol., v. 18, n. 4, p. 1157-1165, 2004.

EMPRESA BRASILEIRA DE PESQUISA AGROPECUÁRIA - EMBRAPA. Sistema brasileiro de classificação de solos. Brasília: 1999. 412 p.

FLECK, N. G. Doses reduzidas de herbicidas de pósemergência para controle de papuã em soja. Planta

Daninha, v. 12, n. 1, p. 21-28, 1994.

FLECK, N. G. et al. Período crítico para controle de Brachiaria plantaginea em função de épocas de semeadura da soja após a dessecação da cobertura vegetal. Planta Daninha, v. 20, n. 1, p. 53-62, 2002

FLECK, N. G.; CUNHA, M. M.; VARGAS, L. Dose reduzida de clethodim no controle de papuã na cultura da soja, em função da época de aplicação. Planta Daninha, v. 15, n. 1, p. $18-24,1997$

HALL, M. R.; SWANTON, C. J.; ANDERSON, G. W. The critical period of weed control in grain corn (Zea mays). Weed Sci., v. 40, n. 3, p. 441-447, 1992.

HAMILL, A. S. et al. Benefits and risks of economic vs. efficacious approaches to weed management in corn and soybean. Weed Technol., v. 18, n. 3, p. 723-732, 2004.

JOHNSON, G. A.; HOVERSTAD, T. R. Effect of row spacing and herbicide application timing on weed control and grain yield in corn (Zea mays). Weed Technol., v. 16, n. 3, p. 548-553, 2002.

MAEHLER, A. R. Crescimento e rendimento de duas cultivares de soja em resposta ao arranjo de plantas e regime hídrico. 2000. 108 f. Dissertação (Mestrado em Fitotecnia) - Universidade Federal do Rio Grande do Sul, Porto Alegre, 2000.

MOHLER, C. L. Enhancing the competitive ability of crops. In: LIEBMAN, M.; MOHLER C. L.; STAVER, C. P. (Eds.) Ecological management of agricultural weeds. Cambridge: Cambridge University Press, 2001. p. 269-322.
MOORE, S. H. Uniformity of plant spacing effect on soybean population parameters. Crop Sci., v. 31, n. 4, p. 1049-1051, 1991.

NAZARKO, O. M.; van ACKER, R. C.; ENTZ, M. H. Strategies and tactics for herbicide use reduction in field crops in Canada: a review. Can. J. Plant Sci., v. 85, n. 2, p. $457-479,2005$

O'DONOVAN, J. T. et al. Barley seeding rate influences the effects of variable herbicide rates on wild oat. Weed Sci., v. 49, n. 6, p. 746-754, 2001.

PIRES, J. L. F. et al. Redução na dose de herbicida pósemergente e no espaçamento entre linhas para controle de papuã em soja. Planta Daninha, v. 19, n. 3, p. 337-343, 2000 .

PIRES, J. L. F.; COSTA, J. A.; THOMAS, A. L. Rendimento de grãos de soja influenciado pelo arranjo de plantas e níveis de adubação. Pesq. Agropec. Gaúcha, v. 4, n. 2, p. 183-188, 1998.

POPP, M. P. et al. Evaluation of seedbed preparation, planting method, and herbicide alternatives for dryland soybean production. Agron. J., v. 92, n. 6, p. 1149-1155, 2000 .

REUNIÃO DE PESQUISA DE SOJA DA REGIÃO SUL, 32., 2004, Passo Fundo. Recomendações técnicas para a cultura da soja no Rio Grande do Sul e em Santa Catarina 2004/2005. Passo Fundo: Embrapa Trigo, 2005. 170 p.

RIZZARDI, M. A.; FLECK, N.G. Dose econômica ótima de acifluorfen + bentazon para controle de picão-preto e guanxuma em soja. Planta Daninha, v. 22, n. 1, p. 117-125, 2004.

SAS Institute. SAS/STAT User's guide. Cary: 1999. 943 p.

VAN ACKER, C. R.; SWANTON, C. J.; WEISE, S. F. The critical period of weed control in soybean [Glycine $\max (\mathrm{L}$. Merr.]. Weed Sci., v. 41, n. 2, p. 194-200, 1993

VENTIMIGLIA, L. A. et al. Potencial de rendimento da soja em razão da disponibilidade de fósforo no solo e dos espaçamentos. Pesq. Agropec. Bras., v. 34, n. 2, p. 195199,1999.

WALKER, S. R. et al. Improved management of Avena ludoviciana and Phalaris paradoxa with more densely sown wheat and less herbicide. Weed Res., v. 42, n. 4, p. 257-270, 2002.

ZHANG, J.; WEAVER, S. E.; HAMILL, A. S. Risks and reliability of using herbicides at below-labeled rates. Weed Technol., v. 14, n. 1, p. 106-115, 2000. 